\title{
STUDY ON A BRAIN-CONTROLLED PNEUMATIC ACTUATOR TO ASSIST EMERGENCY BRAKING OF A VEHICLE
}

\author{
Ryszard Dindorf*, Jakub Takosoglu, Piotr Wos \\ Kielce University of Technology, Kielce, Poland \\ *E-mail of corresponding author: dindorf@tu.kielce.pl

\section{Resume} \\ This article deals with the issue of safety within the road freight transport \\ sector with regards to the securing of cargo on a vehicle. The first part of the \\ article focuses on the legal framework that regulates this issue in the Czech \\ Republic. The second part is based on a case study and survey conducted \\ among drivers of the road freight transport vehicles into their awareness of \\ what they understand is meant by securing and secure cargo. The case study \\ was carried out in a specific transport company and includes an analysis \\ of the current situation and concrete measures for improving safety while \\ securing timber for transport.
}

Department of Manufacturing Engineering and Metrology, Faculty of Mechatronics and Mechanical Engineering,

Available online: https://doi.org/10.26552/com.C.2021.3.F49-F57

\section{Article info}

Received 17 September 2020

Accepted 6 November 2020

Online 18 March 2021

\section{Keywords:}

road freight transport, lashing and securing cargo, safety, case study
ISSN 1335-4205 (print version) ISSN 2585-7878 (online version)

\section{Introduction}

Automotive manufacturers are currently trying to implement autonomous driving (ADV) technology. Along with the progress of innovative technology, new cases of using the ADV in means of transport will appear, which largely depend on the type of a vehicle and their location. According to press reports, the final ADV implementation plan is a car without a driver. However, in autonomous vehicles, various human intentions are incorrectly recognized. The human brain provides a lot of information about the driver's cognitive and emotional states that are associated with various road events [1]. Developing a brain-computer interface (BCI) strategy and automatic driving can bring benefits to car traffic safety [2]. The purpose of various studies is to use the brain (mind) in vehicle control systems or their particular mechanisms. Particular solutions, such as a brain-controlled car for people with disabilities, are also being considered. In paper [3], was presented a car for a disabled person, in which read brain signals and controls the car accordingly. The limitations of the BCI lead to poor vehicle control by the driver's brain. To improve efficiency and safety of a brain-controlled car, a novel assistant controller designed by using the model predictive control method was proposed [4]. The brain-controlled vehicles can provide a way for people with disabilities to improve their mobility. These are revolutionary changes in a society in which the distinction between abled and disabled driver will vanish. The driver-vehicle interface (DVI), based on electroencephalogram (EEG) signals, translates these signals into driving-related commands [5]. Chinese engineers from Nankai University in Tianjin have developed a system that can read brain signals and control a car accordingly. In paper [6], it was considered to develop a brain-driven car that would be very helpful for people with physical disabilities. The car works on the asynchronous mechanism of artificial intelligence. Several papers [7-8] considered developing an EEGbased brain-controlled car, that could be used by people with physical disabilities. At the same time, various brain states that were the result of different patterns of neural interaction were taken into account. Brain patterns are characterised by different brain wave frequencies, e.g. beta waves between 12 and $30 \mathrm{~Hz}$ are associated with concentration while alpha waves between 8 and $12 \mathrm{~Hz}$ are associated with relaxation and a state of mental calm [9]. The contractions of muscles within the head are also associated with unique wave patterns and isolating these patterns is a way to detect the driver's emotional states [10]. The emotional state of the driver directly affects the reaction time during the emergency braking. Based on the literature data, the pressure force and the reaction time of an abled driver during the emergency braking were analysed [11]. Manning [12] registered a mean peak force of $750 \mathrm{~N}$ while braking and found no statistical difference 


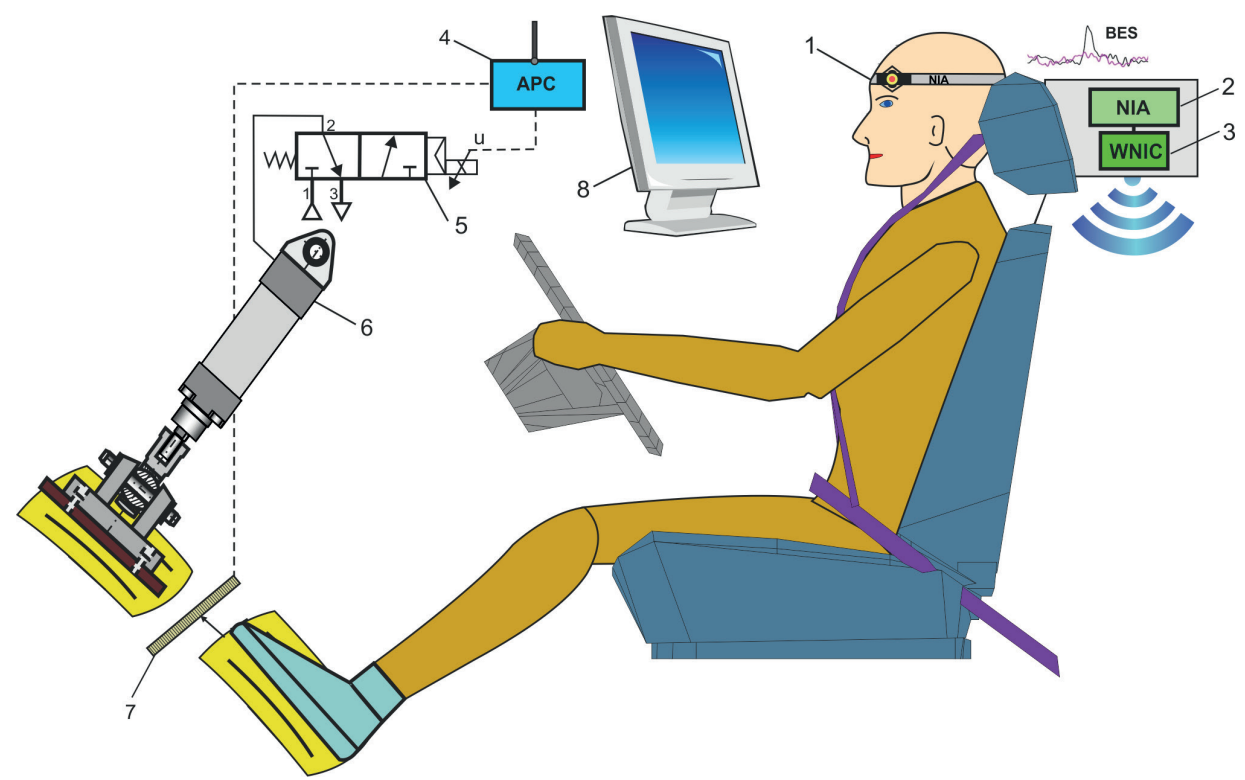

Figure 1 Simulator for a pneumatically assisted emergency braking of a vehicle: 1 - headband with surface electrodes, 2 - neural impulse actuator (NIA), 3 - wireless network interface controller (WNIC), 4 - actuator position controller (APC), 5 - pneumatic control valve, 6 - pneumatic actuator assembly, 7 -sensor of a brake pedal deflection, 8 - monitor screen.

between men and women. According to [13] average brake force in the emergency braking event was $796 \mathrm{~N}$ and the reaction time was $0.5 \mathrm{~s}$. In the emergency braking event, the simulated average speed was $67 \mathrm{~km} / \mathrm{h}$. Furthermore, it was shown that in an emergency it is more common to push the brake pedal before using the clutch. It was also clearly stated that subjects who placed their foot higher up on the brake pedal produced a higher maximum brake force. People over the age of 50 produced maximum emergency braking force much more slowly than younger people. The papers [14-17] presents the results of research on the reaction time of drivers of motor vehicles in case of accident risk. These tests have been conducted on the driving simulator. The study in [18] aimed to determine how a driver's foot and ankle forces during a frontal vehicle collision depend on initial lower extremity posture and brake pedal force. Emergency Brake Assist (EBA) is a new technology being developed in vehicles [19]. The EBA, sometimes called Brake Assist (BA), detects danger and ensures as shortest braking distance as possible. Research conducted on the driving simulator revealed that more than $90 \%$ of drivers fail to brake with enough force when faced with an emergency. By interpreting the speed and force with which the brake pedal is pushed, the EBA system detects if the driver is trying to execute an emergency stop and if the brake pedal is not fully applied, the Anti-Lock Braking System (ABS) takes. Each car manufacturer has its own emergency braking system technology, but they all rely on some type of sensor input. Mostly speed with which a brake pedal is depressed. The EBA system is often combined with other brake systems like AEB, ESP and ABS.

The authors conducted a study on use of the bioelectric signals to control pneumatic systems [20]. This solution was used to safely control the pneumatic servo drives. The emergency stop of a pneumatic cylinder using "thoughts" was analysed. However, in paper [21] they presented a new design of a wearable orthosis of the elbow joint with a bi-muscular pneumatic servo-drive with control based on the recording of bioelectric signals. In this study, an innovative solution, involving use of the brain-controlled pneumatic cylinder to exert the pressure force on the foot brake pedal in the car, for a disabled driver during the emergency braking, was proposed. A pneumatic cylinder assembly has been adopted to exert the required pressure on the foot brake pedal. The pneumatic cylinder assembly is removable, so it can also be used for accurate and rapid testing procedures of brake systems, e.g. on car assembly lines. Further tests will be carried out in the real driving conditions. Then, the car will have additional equipment to ensure safe driving, such as obstacle detection and avoidance systems. If the developed braking assistance system becomes a cost-effective way and it will be possible to enable more functions. In the future, brain support for driving systems such as automatic navigation systems, automatic speed control mechanisms, traffic signals and signboard detection and automatic car starting mechanism will be analysed.

\section{Simulator design solution}

Simulator of authors' design solution for a pneumatically assisted emergency braking system of a vehicle, based on the driver's brain activity, is shown in Figure 1. The driver is seated in front of a monitor screen on which various road incidents affecting his emotional state are simulated. The neural impulse actuator (NIA), as a recording device, contains a headband with three surface electrodes, a control box and communication 


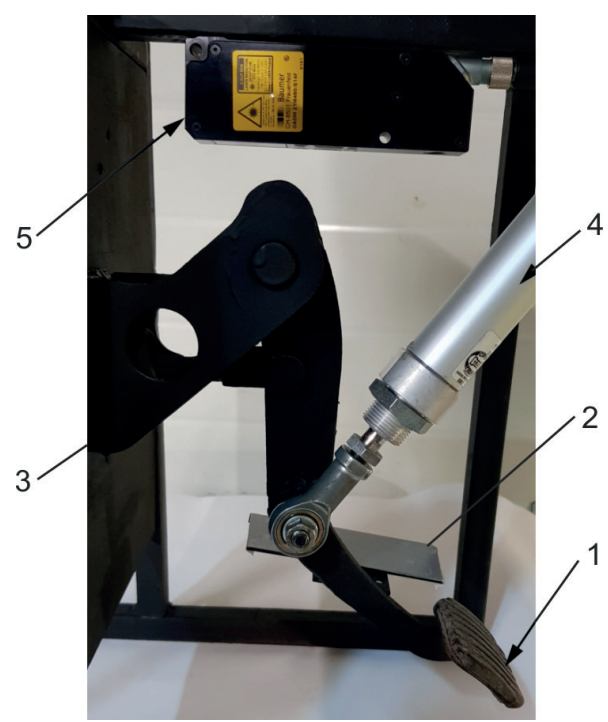

Figure 2 View of the space of the dual foot brake pedals:

1 - primary foot brake pedal, 2 - secondary foot brake pedal,

3 - brake pedal mechanism, 4 - pneumatic actuator, 5 - laser sensor.

software with a wireless network interface controller (WNIC). The NIA analyses bioelectric signals (BESs) induced by the driver brain activity, then decodes them into control signals sent by a WNIC to the actuator position controller (APC).

The NIA is a non-invasive device, which reads the BESs caused by the brain activity (as a result of brain waves, i.e. electroencephalogram signals (EEG) and by muscle tension inside the head (movement of the face and eyelids, clenching of jaws, pressing the tongue on the palate, etc. EMG - electromyography signals) [22]. The NIA device as a BCI improves the BESs to the form of control signals useful for controlling the pneumatic actuator. Effective control of the pneumatic control system with use of the NIA requires a snug fit of the sensors to readers of BESs, calibration of the device and training of the test participants (drivers). To test the use of biosignals and wireless communication in control of a pneumatically actuated foot brake pedal, a wireless network interface controller (WNIC) was built. A WNIC enables a high-fidelity control signal to be streamed to a Wi-Fi-connected device in real-time. The wireless communication does not distort the control signals and does not limit the movement of the driver while driving a car. The actuator position controller (APC) enables to control the movement of the pneumatic actuator by an electrical input signal task to a directional 3/2-way solenoid pilot operated valve. The $3 / 2$ directional valve is always closed in the neutral position (NC normally closed), i.e. when the valve is not activated. Upon the electrical signal task, the valve opens and the actuator piston extends and presses on the secondary foot brake pedal (braking state). When the electric signal disappears, the cylinder piston retracts immediately (brake release state). The APC receives a feedback signal from the position transducer of the secondary brake pedal. The measuring system is designed to check the position of the brake foot pedal and protection against uncontrolled movement of the pneumatic actuator. The triangulation laser sensor, with an output signal in the range of $0-4.74 \mathrm{~V}$, ensures the measurement of the pedal deflection up to $80 \mathrm{~mm}$. Figure 2 shows the view of the dual foot brake pedals space in which a pneumatic actuator presses the foot brake pedal and the laser sensor measures the deflection of the brake pedal. The pressure force of the pneumatic cylinder on the secondary foot brake pedal is constant over the entire stroke range. In contrast, the primary foot brake pedal pressure, felt by the driver's foot, increases gradually but it will be significantly felt when the brake pedal reaches a height of $50 \%$ of the available deflection. Braking becomes effective only when the brake pedal deflection exceeds $60 \%$ of the available deflection,

\subsection{Dual foot brake pedals}

The dual control systems are installed in cars to ensure driving safety in special conditions. The dual control systems in the car relate especially to the auxiliary devices such as clutch pedals, brake pedals and acceleration pedals, which are located on the passenger side. Such dual control is installed mainly in driving schools, but it can also be useful for people who require checking while driving. The dual brake pedals themselves have been introduced to increase the safety standard and driving comfort for certified driver rehabilitation specialists, who supervise disabled drivers. The dual brake pedals can also be used by people who want to extend the training period in a family vehicle. In this case, the dual brake pedals are ideal for the long-term use beyond the training evaluation period, reducing risk and stress for both the driver and passenger. A disabled driver during the independent 


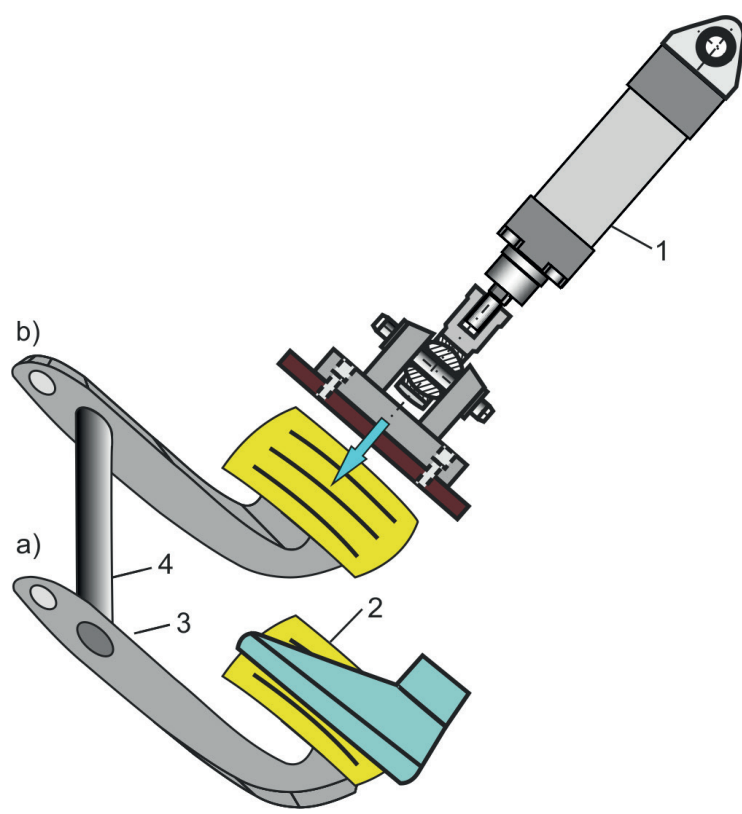

Figure 3 Dual foot brake pedals: a) primary driver brake pedal, b) secondary brake pedal with pneumatic assistance, 1 - pneumatic actuator assembly, 2 - brake pedal pad, 3 - brake pedal arm, 4 - tubular shaft.

driving can react to road hazards with some delay, especially during the emergency braking. A new solution of the dual foot brake pedals, consisting of the primary driver pedal and the secondary pedal pressed by the pneumatic actuator is shown in Figure 3. The primary foot brake pedal is rigidly connected to the secondary pedal by a tubular shaft. The driver presses his feet on the primary foot brake pedal while braking the vehicle under normal driving conditions. A spring returns the pedals to the upper (resting) position when the driver's foot is removed from the pedal. In the case of emergency braking, the pneumatic actuator presses the secondary brake pedal faster before the driver starts pressing the primary brake pedal with his foot. The secondary foot brake pedal is pressed by a pneumatic cylinder, which is controlled by the driver as a result of his brain activity during the emergency braking. When relaxing the driver, the pneumatic actuator releases the pressure on the secondary brake pedal. The dual braking system ensures greater driving safety because the secondary brake pedal is pneumatically pressed when the disabled driver cannot press the primary brake pedal in due time.

\subsection{Pneumatic actuator assembly}

The design solution of a pneumatic actuator assembly with mounting accessories is shown in Figure 4.

A standard pneumatic actuator ISO 6432 (Prema S.A., Poland), with the $D=25 \mathrm{~mm}$ piston diameter and the $S=100 \mathrm{~mm}$ stroke, was used. The pneumatic actuator used in the pneumatic assembly is a singleacting cylinder with a single-piston rod. In a singleacting actuator, compressed air is supplied only to one

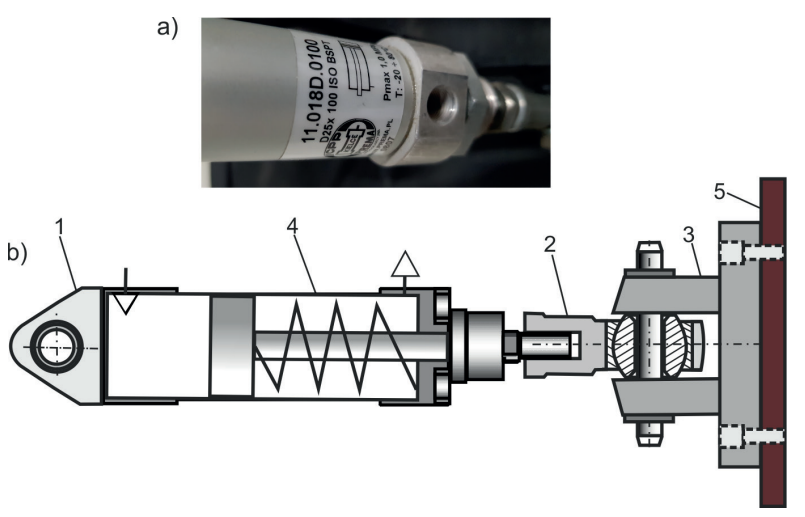

Figure 4 Pneumatic actuator assembly: a) view of pneumatic actuator, b) design solution of an actuator assembly, 1 - pneumatic actuator (single-acting cylinder), 2 - spherical rod-end, 3 - cap-end female clevis, 4 - articulated male rear hinge, 5 - contact pad.

side of the piston surface. The other side is open to the atmosphere. The single-acting actuator uses compressed air energy only for the working stroke, movement in one direction. The return movement of the piston is effected by a built-in spring. The presented pneumatic actuator assembly is adapted to exert a specific pressure on the secondary foot brake pedal in a car. When selecting the stroke of the pneumatic actuator, it was assumed that the brake pedal sits $160 \mathrm{~mm}$ from the floor, when this distance is measured perpendicular to the front face of the pedal. As the brake pedal is pressed by the contact pad of the pneumatic actuator, it rotates through an arc. This angle can be up to $40^{\circ}$ depending on the vehicle type. The total brake pedal deflection is $80 \mathrm{~mm}$. The free displacement of the brake pedal, which may be around $6 \%$ of the available deflection, must be taken into account.

\subsection{Neural impulse actuator}

The neural impulse actuator (NIA) device by OCZ is a BCI type interface equipped by a neuro signal reader [23]. Signals, originating from the neural activity of the brain, are captured by the NIA in the form of electrical biopotentials, which occurred as a result of Alpha and Beta brain waves, movement of the facial muscles and eyelids. The NIA is a non-invasive device that was used as a brain-machine interface (BMI), that reads bioelectrical signals (BESs) caused by brain activity, muscle tension in the head and during eye movement. The NIA offers interpretation of the raw EEG (electroencephalography) and EMG (electromyography) data, as well as their translation into an understandable frequency spectrum. 

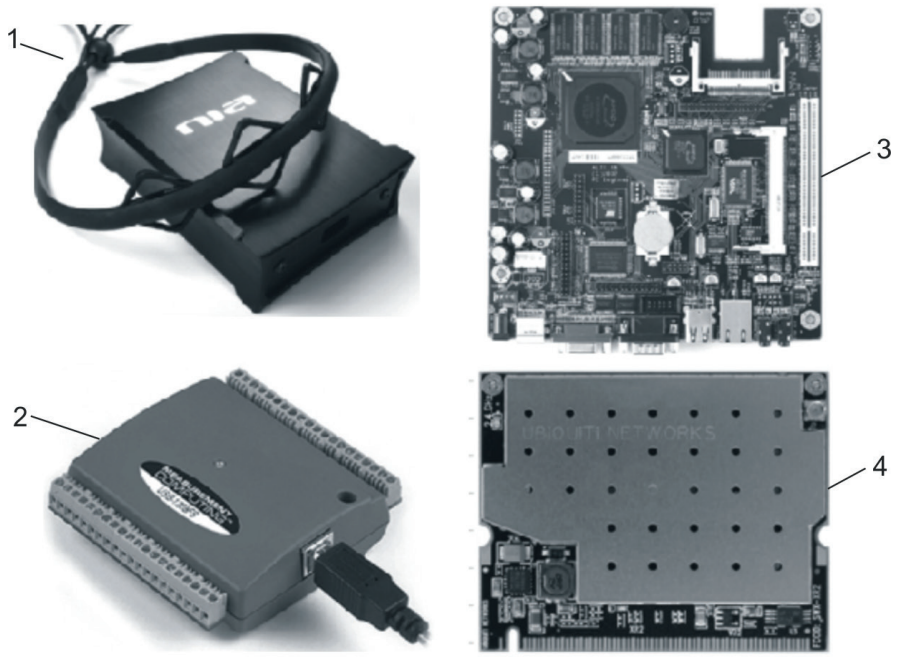

Figure 5 Control system: 1 - NIA set, 2 - data acquisition device, 3 - microcomputer board, 4 - wireless card

The EEG records a series of brain waves and EMG records muscle movement. The NIA is composed of a control box, client software and a headband with three diamond-shaped sensors, which are put on the driver's forehead. In the control box, recorded BES are analyzed, translated and sent to the NIA client software suite for further processing. The client software relays the binary impulse signals sent from the control box and passes them onto an executable program based upon the command specifications. The software provided with the NIA enables calibration and defining the control profiles creating applications. The rubber headband consists of three diamond-shaped conductor plates with BESs sensors based on carbon nanofibers (CNFs), that are bound to the forehead. Effective control of technical devices with use of the NIA requires a snug fit of the BESs sensors to the forehead, calibration of the device and training.

\subsection{Simulator control system}

The simulator control system consists of the NIA, microcomputer board ALIX.1D PC, data acquisition device MicroDAQ USB-1208FS and a wireless card Ubiquiti XR2 WiFi card (see Figure 5). The ALIX.1D system board is equipped by an AMD Geode $500 \mathrm{MHz}$ processor and $256 \mathrm{MB}$ of RAM. It is powered by a 12 $\mathrm{V}$ supply and has the low power consumption, in the range of 0.4 to $0.5 \mathrm{~A}$. The software for the servo drive and controller was written using the LabVIEW environment. The task of the system board is to integrate the wireless card, IO port and the controller application. The Windows operating system has been installed on the memory card. Since the controller requires $+24 \mathrm{~V}$ supply the device uses a step-down voltage regulator built on an LM2576 system to reduce the voltage to the required $12 \mathrm{~V}$. The I/O port for the controller is the MicroDAQ USB-1208FS data acquisition module, connected with the controller board via a USB cable. This module includes 12-bit differential analogue inputs and 11-bit single-ended inputs. In the single-ended mode, a \pm 10 $\mathrm{V}$ measurement is possible, whilst in the differential mode, $\pm 20 \mathrm{~V}$. Two 12-bit analogue outputs are available for generating output signals. The output voltage range is $0 \div 4.096 \mathrm{~V}$ under a maximum load of $15 \mathrm{~mA}$. Due to the low output voltage, a $k_{u}=2.5$ preamplifier was installed on the controller to obtain a $10 \mathrm{~V}$ output signal. The preamplifier was built on the LM358 Op Amp system. Use of a rail-to-rail amp is connected with the asymmetric controller supply current.

Two applications were written, the first for communication between the NIA control box and the computer and the second for controlling the pneumatic actuator. Both applications were written using LabVIEW software. Data are sent via a wireless IT network, which enables the use of the TCP and UDP wireless transmission protocols. The TCP protocol ensures reliable delivery of data to the receiver using follow, confirm and retransmit functions for the data. The second UDP protocol has a simpler structure and is faster, but does not ensure the retransmission of lost data. For the position control of the pneumatic actuator, a PID controller was used, with tuning carried out by the Ziegler-Nichols method.

\section{$3 \quad$ Biosignal processing}

Currently, the tendency to use the bioelectric signals to control technical devices is increasing. The brain provides a lot of information about a person's physiological, emotional and cognitive states, which, when properly selected, can be used for various purposes. Brain activity accompanying their various states is reflected in the BES waves of varying range and frequency. Reading the BES is generally described in terms of its amplitude and frequency band. The amplitude of the EEG shows a great 


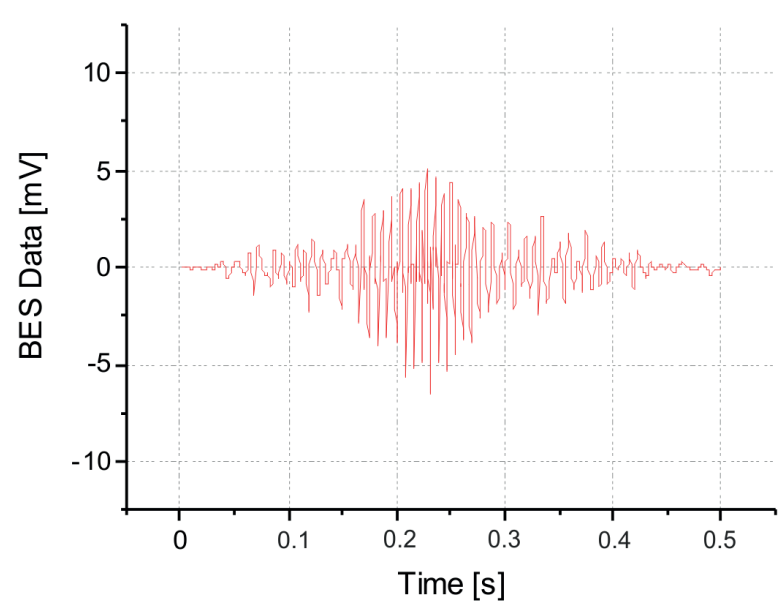

Figure 6 Recorded time-dependent BESs spectrum activated by the muscle tension inside the head.

deal of variability depending on external stimulation, as well as internal mental states. Electrodes located on the scalp register brain wave activity, which results in the user being able to issue commands by "thought". These electrodes also read muscle tension in the head area, which result from brain activity. The brain activity causes a change in biosignals that can be measured and used as control signals. Biosignals are space, time, or space-time records of a biological event such as a brain activity or a contracting muscle. The electrical and mechanical activity that occurs during the biological events produces signals that can be measured and analysed. Biosignals, therefore, contain useful information that can be used to understand the underlying physiological mechanisms of a specific biological event or system and that may be useful for technical. Basic methods of signal analysis, such as amplification, filtering, digitization, processing and storage, can be applied to many biological signals [24].

Once the NIA has captured the BESs, they are analysed and separated through the Fast Fourier transforms (FFT) into different frequencies to be translated into commands that the user defines as control signals to activate the pneumatic actuator of the secondary brake pedal. To obtain the extension of the actuator down (pressure force on the brake pedal) and retract the actuator up (release the pressure force on the pedal) control commands were selected, $u=$ (down, up). Figure 6 shows the recorded time-dependent BES spectrum activated by muscle tension in the head. However, Figure 7 shows the recorded BES frequency spectrum activated by the muscle tension in the head.

There are two main problems during the detection, recording and decoding of the BESs to command signals. The first problem is the signal to noise ratio. The second problem is the noise signal defined as an electrical signal that is not a part of the desired BES. Research on the BESs shows that distinction of mental tasks can be carried out selectively in selected frequency bands. The measured BESs can be processed to eliminate noise or other possible interference. Initial biosignal processing

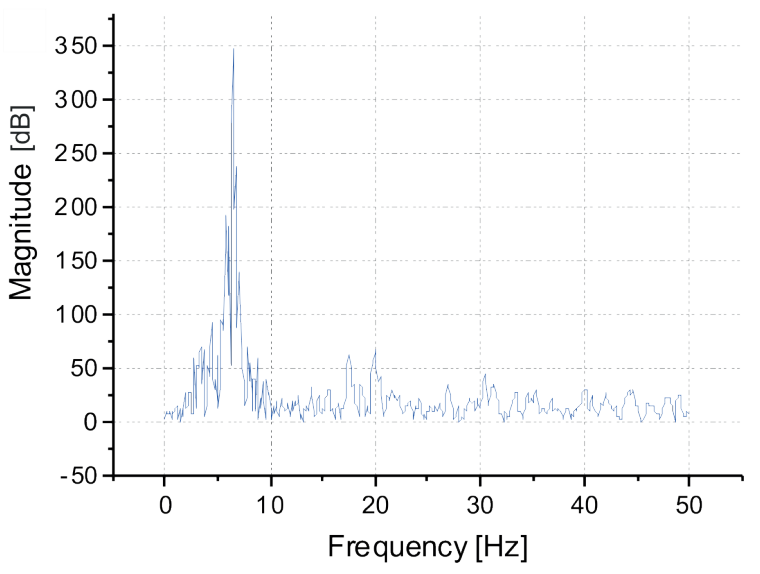

Figure 7 Recorded BESs frequency spectrum activated by the muscle tension inside the head.

usually involves signal filtration and removing noise and interference. At this stage, digital filters, spatial filters and signal whitening methods are used. These different approaches have been considered to perform the analysis in the frequency domain and to compute power spectral density (PSD) of the BES. Features, obtained using the discrete Fourier transform (DFT), illustrate the amplitude of the signal for individual frequency components, can be written as [25]:

$$
X_{i}(k)=\sum_{n=0}^{M-1} x_{i}(n) w(n) e^{-j} \quad \omega_{k}^{n} 1 \leq i \leq K,
$$

where $x_{i}$ is the measured BES as the input variables, $n$ is the number of the signal sample, $M$ is the samples per segment, $K$ is the smaller segment, $w(n)$ is the windows, $\omega_{k}$ is the discrete frequency of DFT, $\omega_{k}=2 \pi k / N, k$ is the frequency bins, $N$ is the number of samples, $N=M R, R$ is the number of non-overlapping frames.

The power spectrum, according to the second modification made by Welch to Bartlett's method, is [26]:

$P_{i}(k)=\frac{1}{M U}\left[X_{i}(k)\right]^{2}$,

where $U$ is the normalisation factor for the power spectrum in the window function $w(n)$ :

$U=\frac{1}{M} \sum_{n=0}^{M-1} w^{2}(n)$.

Based on Equation (2), the main power spectrum in a frequency band for a limited time can be calculated as:

$P_{m}(k)=\frac{1}{K} \sum_{i=1}^{K-1} P_{i}(k)$.

For the real signals, due to the symmetry of the spectrum, it is sufficient to account for a half of the N/2 stripes only. It is known that the useful biosignal band is in the range from $0.5 \mathrm{~Hz}$ to $50 \mathrm{~Hz}$. Due to the overall power spectrum, it is possible to identify a disturbance of the bio-potential baseline and distinguish it from increased brain activity. The BESs electrical potentials have both positive and negative voltage. To convert 


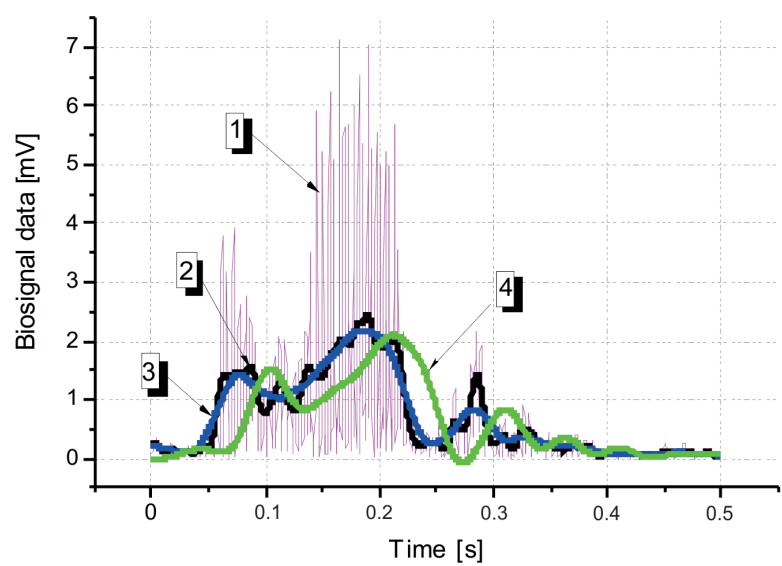

Figure 8 Processing for smooth BES data: 1 - measured BES data (absolute value), 2 - FFT filter, 3 - Lowess method, 4 - Low-pass filter.

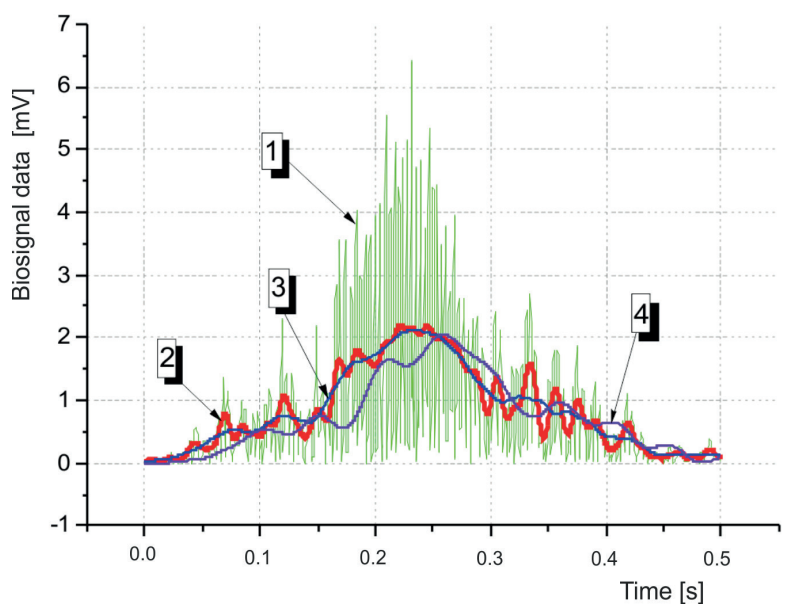

Figure 9 Processing for the smooth BES data: 1 - measured BES data (absolute value), 2 - FFT filter, 3 - Lowess method, 4 - Low-pass filter.

the BES to a user control signal, all the negative amplitudes are firstly converted into positive amplitudes (see Figure 6). The negative peaks are transferred in a positive direction. In addition to transparency of the record, this action aims to obtain the ability to plot curves for the standard amplitude parameters, such as mean, peak - maximum and field values (the raw BES record has an average amplitude value equal to zero). To solve this problem, a unique part of the signal is minimized by using the digital smoothing algorithms that emphasize the main direction in which the biosignal travels. Peaks with excessive amplitude are trimmed and the biosignal is linearized. In addition, a digital smoothing algorithm was used. For smoothing the BESs data, an FFT filter, a lowpass filter (LF) and the Lowess method (LM) was used. The LM also is known as locally weighted polynomial regression (LWPR). The LWPR approximates nonlinear functions in large-dimension spaces with redundant and insignificant inputs. The effect of the BES data smoothing process is shown in Figure 8.

As a result of the driver's brain activity experiment, it was concluded that the BES with frequencies of up to $50 \mathrm{~Hz}$ and amplitudes of several $\mathrm{mV}$, caused by muscle

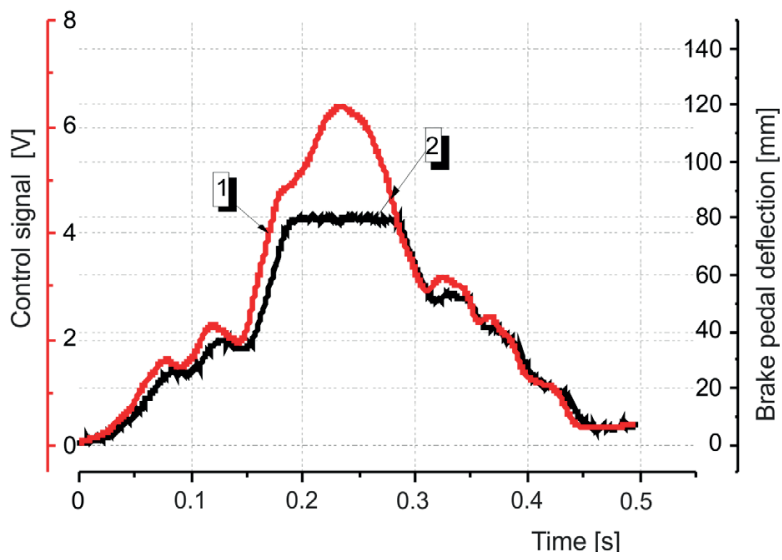

Figure 10 Test results of emergency braking: 1 - control signal based on Lowess method filter, 2 - brake pedal deflections measured with a laser sensor.

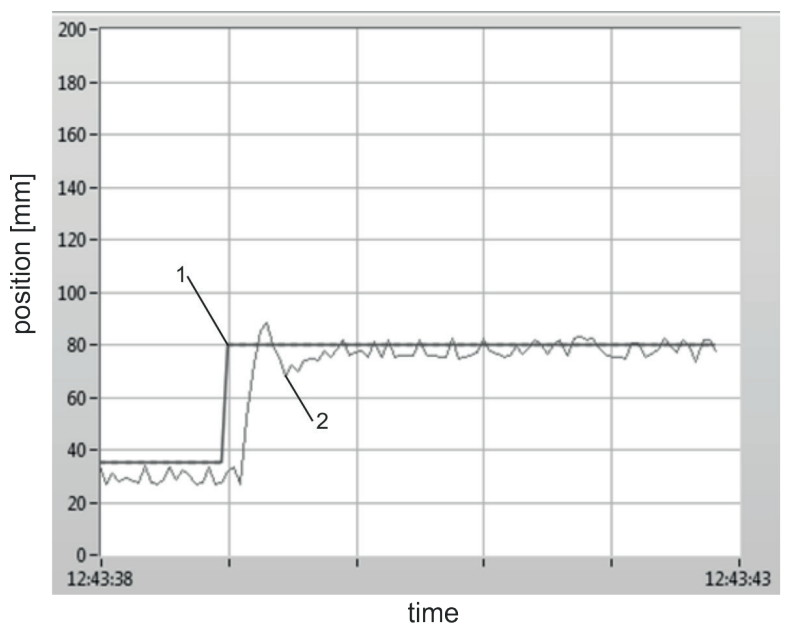

Figure 11 Results of pneumatic actuator position control: 1 - set position, 2 - current position.

tension in the head, e.g. pressing the tongue against the palate or clenching of jaws with a bigger or smaller force, provides the best effects of the position control signals of the pneumatic actuator generation, that presses on the secondary foot brake pedal. Accuracy of the pneumatic actuator movement and the brake pedal deflection can be increased by the driver training on the driving simulator.

\section{Emergency braking test}

Results of the first tests on a brain-controlled pneumatic actuator to assist vehicle emergency braking have been published in a scientific letter [27]. The drivers' ability to generate biosignals at a sufficient level can be achieved through appropriate exercises. During the tests, the effect of various biosignals, decoded on the signals controlling the pressure force of the pneumatic actuator on the secondary brake pedal, was analyzed. Various driver activities generating biopotential were taken into account, such as eyeball movement, muscle movement on the forehead, or moving the jaw, heavy 
thinking and relaxing, or closing the eyes. The best effects were obtained at pressing the tongue against the palate or clenching of jaws with a greater or lesser force. The time-dependent BES spectrum when the tongue is pressed to the palate and the smoothing process this spectrum is shown in Figure 9. Processed biosignals are amplified to input control signals in the range of 0-10 V, which are used to valve control of the pneumatic systems. Practical tests of control of the pneumatically assisted braking system that were carried out confirmed the assumptions of using the driver's brain activity for the emergency braking. Sample results of practical tests, carried out on the test stand, showing control signals based on the LM smoothing, are presented in Figure 10. The graphs in Figure 10 show that there is a delay between the control signal of the pneumatic actuator and the measurement signal of the brake pedal deflection, which affects the slowing down the braking of a vehicle. This delay is due to data acquisition and the process of generating and processing the control signal.

The reaction time $t_{r}$ of the pneumatically assisted emergency braking is the sum of the processing time $t_{p}$ of the biological signal (see Figure 9 based on the tests) and the stroke time $t_{s}$ of the pneumatic actuator:

$$
t_{r}=t_{p}+t_{s}=0.23+0.01=0.24 \mathrm{~s} .
$$

The task of controlling the pneumatic actuator was not to precisely position it, but only to rapidly extend the piston rod. Figure 11 shows the position control results of a pneumatic actuator for a step input signal. The above graphs show that there is a delay between the value of the input signal and the actuator response. With a rapid increase in the control command, the delayed valve actuation and movement of the pneumatic actuator are always technically justified.

Tests carried out on the simulator confirmed that a brain-controlled pneumatic actuator can be used to assist the emergency braking of the vehicle.

\section{Conclusions}

In this study, the possibilities of using a driver's brain activity to pneumatically actuate a secondary foot brake pedal were analysed. The idea of this solution is to use the driver's brain activity for wireless remote control of the pneumatic actuator that exerts pressure on a secondary foot brake pedal during the vehicle emergency braking. For this purpose, a simulator according to authors' design solution, to test the pneumatically actuated foot brake pedal based on the driver's brain activity, was built. The simulator, equipped by the dual foot brake pedals, was used. A pneumatic actuator assembly was also designed, which has been adapted to exert pressure on the secondary foot brake pedal. The designed control system consists of devices for reading the bioelectric signals, analysing and decoding them into the control signals, as well as amplifying, transforming and wireless transmission of the control signals to the position controller of the pneumatic actuator. The recording device, the neural impulse actuator (NIA), reads and analyses the bioelectric signals (BESs), induced by the driver's brain activity, then decodes them into the control signals sent by wireless network interface controller (WNIC) to the actuator position controller (APC). As a result of the experiment, it was found that BESs artefacts are easy and stable to be recognized on the driver's head. As a result of the experiment, it was concluded that the biopotential artefacts caused by muscle tension in a driver's head, e.g. pressing the tongue against the palate or clenching of jaws with a greater or lesser force, generate bioelectric signals with a frequency of up to $50 \mathrm{~Hz}$ and an amplitude of several $\mathrm{mV}$, which can be decoded into a command that control of the pneumatic actuator. The dual brake pedals are justified if it is necessary to increase the driving safety of the less experienced drivers, including disabled drivers, when an accompanying person cannot help them. During the emergency braking, the pneumatic actuator presses the secondary foot brake pedal. After using the pneumatic assistance, the driver's reaction time during the emergency braking is shortened, thus increasing driving safety. The driver's ability to use a pneumatically assisted secondary foot brake pedal by brain activity depends on training on a braking simulator. The main goal of the study was achieved, i.e. increased driving safety by shortening the driver's reaction time during emergency braking.

\section{References}

[1] FAIRCLOUGH, S. H., GILLEADE, K., NACK, L. E., MANDRYK, R. L. Brain and body interfaces: designing for meaningful interaction. In: SIGCHI Conference on Human Factors in Computing Systems: proceedings. 2011. ISBN 978-14503-0228-9, p.1-4.

[2] LI, W., DUAN, F. A human-vehicle collaborative simulated driving system based on hybrid brain-computer interfaces and computer vision. IEEE Transactions on Cognitive and Developmental Systems [online]. 2017, 10(3), p. 1-13. ISSN 2379-8920, eISSN 2379-8939. Available from: https://doi.org/10.1109/TCDS.2017.2766258

[3] SOLANKE, P.B., PATIL, S.P., SHENDE, P.S. Mind-driven vehicle for disabled person using intelligent system. International Journal of Innovative Studies in Sciences and Engineering Technology. 2017, 3(5), p. 38-42. ISSN 2455-4863. 
[4] BI, L., WANG, M., LU, Y., GENETU, F. A. A shared controller for brain-controlled assistive vehicles. In: IEEE International Conference on Advanced Intelligent Mechatronics AIM: proceedings [online]. IEEE. 2016. ISBN 978-15090-206-6. Available from: https://doi.org/10.1109/AIM.2016.7576754

[5] BI, L., ZHANG, J., LIAN, J. EEG-based adaptive driver-vehicle interface using variational autoencoder and PI-TSVM. IEEE Transactions on Neural Systems and Rehabilitation Engineering [online]. 2019, 27(10), p. 1-9. ISSN 1534-4320. Available from: https://doi.org/10.1109/TNSRE.2019.2940046

[6] NARESH, P., HARI BABU, A. V., SUDHAKA REDDY, M., SAI, P. Brain controlled car for disabled using artificial intelligence. Journal of Advancement in Engineering and Technology [online]. 2016. 3(4), p. 1-3. ISSN 2348-2931. Available from: https://doi.org/10.5281/zenodo.999315

[7] SAIKRISHNA, D., EPHRAM, N., AHAMED, S., RAJESWARI, M. Brain controlled car for disabled using EEG. International Journal for Research Trends and Innovation. 2017, 2(3), p. 83-88. ISSN 2456-3315.

[8] THILAGAVATHI, S., AKSHAYA, B., KUMUTHA RAJESWARI, G., PRIYANKA, K. Brain controlled car for disabled using blue brain technology. International Journal of Pure and Applied Mathematics. 2018, 119(15), p. 1613-1618. ISSN 1314-3395.

[9] MAHMUD, M., HAWELLEK, D., VALJAMAE, A. Brain-machine interface based on EEG: extracted alpha waves applied to a mobile robot. In: ECSIS Symposium Advanced Technologies for Enhanced Quality of Life: proceedings. 2009. p. 28-31.

[10] TEPLAN, M. Fundamentals of EEG measurement. Measurement Science Review. 2020, 2(2), p. 1-11. ISSN 1335-8871.

[11] SUMMALA, H. Brake reaction times and driver behavior analysis. Transportation Human Factors [online]. 2014, 2(3), p. 217-226. ISSN 1093-9741. Available from: https://doi.org/10.1207/STHF0203_2

[12] MANNING, P., WALLACE, W. A., ROBERTS, A. K., OWEN, C. J.,. LOWNE, R. W. The position and movement of the foot in emergency manoeuvres and the influence of tension in the Achilles tendon. In: 41th Stapp Car Crash Conference: proceedings. 1997. ISBN 0-76-800033-5, p. 195-206.

[13] PALMERTZ, C., JAKOBSSON, L., KARLSSON, A. S. Pedal use and foot positioning during emergency braking. In: JRCOBJ Conference: proceedings. 1998. p. 135-146.

[14] JURECKI, R. S., JASKIEWICZ, M., GUZEK, M., LOZIA, Z, ZDANOWICZ, P. Driver's reaction time under emergency braking a car - research in a driving simulatory. Eksploatacja $i$ Niezawodnosc - Maintenance and Reliability. 2012, 14(4), p. 295-301. ISSN 1507-2711.

[15] JURECKI, R. S., STANCZYK, T. L, JASKIEWICZ, M. Diver's reaction time in a simulated, complex road incident. Transport. 2017, 32(1), p. 44-45. ISSN 1648-4142.

[16] JURECKI, R. S., JASKIEWICZ, M. Analysis of road accidents in Poland over the last ten years. Zeszyty Naukowe, Akademia Morska w Szczecinie. 2012, 32(104), p. 65-70. ISSN 1733-8670.

[17] JURECKI, R. S. An analysis of collision avoidance manoeuvres in emergency traffic situations. The Archives of Automotive Engineering [online]. 2016, 72(2), p. 73-93. ISSN 1234-754X. e-ISSN 2084-476X. Available from: https://doi.org/10.14669/AM.VOL72.ART2

[18] HARDIN, E. C., SU, A., VAN DEN BOGER, A. J. Pre-impact lower extremity posture and brake pedal force predict foot and ankle forces during an automobile collision. Journal of Biomechanical Engineering [online]. 2005, 126(6), p. 770-778. ISSN 1528-8951. Available from: https://doi.org/10.1115/1.1824122

[19] DAY, A. Braking of road in vehicles. Waltham, MA: Elsevier, 2014. ISBN 978-0-12-397314-6.

[20] MAZUR, S., DINDOR, R., WOS, P. Remote control of the electro-pneumatic servo drive using biosignals. Technical Transactions, Mechanics. 2013, 1-M, p. 245-253. ISSN 0011-4561. e-ISSN 2353-737X.

[21] DINDORF, R., WOS, P. Using the bioelectric signals to control of wearable orthosis of the elbow joint with bi-muscular pneumatic servo-drive. Robotica [online]. 2020, 38(5), p. 804-818. ISSN 0263-5747. Available from: https://doi.org/10.1017/S0263574719001097

[22] REYNOLDS, B., WAECHTER, A. Brain-computer interfacing using the neural impulse actuator. A usability and statistical evaluation. Los Angeles, CA: California Polytechnic State University, 2009.

[23] COAKLEY, E. Demonstrating realistic avatar control in a virtual environment through the use of a neural impulse actuator. MS Project: Neural avatar control. Final Report. Lake Forest, CA, 2010.

[24] ENDERLE, J. D., BRONZINO, J. D. Introduction to biomedical engineering. 3. ed. Burlington, MA: Elsevier, 2012. ISBN 978-0-12-374979-6.

[25] PAMPU, N. C. Study of effects of the short-time Fourier transform configuration on EEG spectral estimates. Acta Technica Napocensis, Electronics and Telecommunications. 2011, 52(4), p. 26-29. ISSN 1221-6542.

[26] PROAKIS, J. G., MANOLAKIS, D. G. Digital signal processing. Principles, algorithms and applications. 3rd Ed. Upper Saddle River, NJ, USA: Prentice-Hall Inc., 1996. ISBN 0-13-394338-9.

[27] DINDORF, R., WOS, P. Analysis of the possibilities of using a driver's brain activity to pneumatically actuate a secondary foot brake pedal. Actuators [online], 2020, 9(49), p. 1-13. ISSN 2076-0825. Available from: https://doi.org/10.3390/act9030049 